\title{
Sorption behavior of phosphate by fly ash discharged from biomass thermal power plant
}

\author{
Jong-Hwan Park ${ }^{1 \dagger}$, Se-Wook Hwang ${ }^{2 \dagger}$, Su-Lim Lee ${ }^{2}$, Jae-Hoon Lee ${ }^{2}$ and Dong-Cheol Seo ${ }^{1 *}$
}

\begin{abstract}
This study evaluated the characteristics and mechanism of phosphate adsorption by fly ash discharged from a biomass thermal power plant (BTP-FA) under various environmental conditions in order to increase the recyclability of BTP-FA. The phosphate adsorption properties of BTP-FA and fly ash derived from coal thermal power plant (CTP-FA) were better matched by those predicted by the Langmuir isothermal model and the pseudo-second-order model, and their maximum adsorption capacities were 62.1 and $4.1 \mathrm{mg} / \mathrm{g}$, respectively. It was found that the adsorption of phosphate by BTP-FA was predominantly influenced by the outer boundary layer rather than the inner diffusion in the pores. The phosphate adsorption process by BTP-FA was greatly influenced by the initial pH and the BTP-FA dose. Therefore, to effectively treat phosphate using BTP-FA, the concentration and flow rate of phosphate in the incoming wastewater must be considered. The concentration of dissolved calcium from BTP-FA decreased sharply during the phosphate adsorption process compared to that in the phosphate-free solution. This was thought to be due to surface adsorption/reaction between calcium and phosphate. The SEM-EDS and FTIR results also supported the surface adsorption/precipitation reaction of Ca-P. Recycling fly ash discharged from biomass power plants as phosphate adsorbents is expected to contribute not only to waste reduction, but also to wastewater purification.
\end{abstract}

Keywords: Fly ash, Biomass thermal power plant, Phosphate, Adsorption, Coal

\section{Introduction}

Phosphorus is an essential and important nutrient for the growth of living organisms and ecosystem function [1]. However, due to the excessive use of chemical fertilizers, synthetic detergents, and organic/inorganic phosphorus compounds in agriculture, households, and industries, wastewater containing various forms of phosphorus is discharged into the environment, causing severe water pollution problems [2-4]. In particular, the concentration of phosphorus in water is closely related to symptoms of eutrophication, such as algal growth, oxygen depletion, and the loss of aquatic species [5]. For this reason, the Environmental Protection Agency (EPA) limits

\footnotetext{
*Correspondence: drseodc@gmail.com

${ }^{\dagger}$ Jong-Hwan Park and Se-Wook Hwang have contributed equally to this work

${ }^{1}$ Department of Applied Life Chemistry (Institute of Agriculture and Life Science), Gyeongsang National University, Jinju 52828, South Korea Full list of author information is available at the end of the article
}

the maximum allowable level of phosphorus in treated wastewater to less than $1 \mathrm{mg} / \mathrm{L}$ [6]; according to water quality standards for effluents from public sewage treatment facilities in Korea, the total phosphorus in treated wastewater is required to be less than $0.3 \mathrm{mg} / \mathrm{L}$ [7]. Despite efforts in past decades to reduce the quantities of phosphorus flowing into water systems from environmental pollution sources, water pollution due to phosphorous remains a major environmental problem.

Various techniques and methods, such as chemical precipitation, ion exchange, biological treatment, and adsorption have been developed to remove phosphate from water $[8,9]$. However, methods such as chemical precipitation, ion exchange, and biological treatment require a long hydraulic retention time (HRT) for phosphate treatment, and securing a large site and maintaining the facility for the same is costly [10]. In addition, washing water and sludge containing phosphorus that are discharged from these processes are considered to be 
secondary pollutants [11]. In contrast, removal of phosphorus through adsorption has low initial investment and maintenance costs as well as high removal efficiency, and it has been the focus of many studies over the past decades $[8,9]$.

The most recently developed adsorbents for phosphorus removal are wastes, minerals, and synthetic materials [12, 13]. The application of adsorbents based on minerals and synthetic materials is limited in large-scale adsorption facilities, which have high concentrations of pollutants because of these adsorbents have relatively low adsorption efficiencies and are costly. Therefore, adsorption of phosphate using waste-based adsorbents is attracting attention. Waste-based adsorbents are often eco-friendly and low-cost alternatives because they can effectively remove high phosphorus concentrations and are made of recycled waste.

Fly ash is discharged as a by-product from coal-thermal power plants, and is promising as an adsorbent for removing phosphorus from water because it has sufficient pores and a large amount of $\mathrm{Ca}^{2+}$. Many researchers have reported on the ability of fly ash to adsorb phosphate [14, 15]. However, it has been reported that coal-based fly ash contains many toxic trace elements that can adversely affect the human body and can easily accumulate in soil or elute in water [16]. For this reason, coal-based fly ash is not commonly used as an adsorbent for phosphorus removal. Recently, increasing numbers of coals power plants have been using biomass as a raw material instead of coal due to serious concerns about environmental pollution caused due to emission of airborne pollutants from aging coal-thermal power plants [17]. However, there are no studies related to the adsorption of phosphate by fly ash discharged from biomass thermal power plants. Unlike coal, biomass has a low content of toxic elements. Therefore, this study hypothesizes that fly ash discharged from biomass power plants would have low toxicity and high affinity for phosphorus.

The purpose of this study was to evaluate the characteristics of phosphate adsorption by fly ash discharged from biomass thermal power plants under various environmental conditions, along with the mechanism of this adsorption.

\section{Materials and methods}

\section{Materials}

Fly ash discharged from a biomass and coal thermal power plant (BTP-FA and CTP-FA) were used in this experiment, and they were obtained from a biomass and coal thermal power plant (Korea South-East Power Co., South Korea) (Table 1). The pH of BTP-FA and CTPFA were 12.6 and 8.8, respectively, and BTP-FA showed higher alkalinity than CTP-FA. Generally, the $\mathrm{pH}$ of
Table 1 Chemical properties of BTP-FA and CTP-FA

\begin{tabular}{lll}
\hline Parameter & BTP-FA & CTP-FA \\
\hline $\mathrm{pH}(1: 10)$ & 12.6 & 8.8 \\
$\mathrm{~K}_{2} \mathrm{O}(\%)$ & 1.29 & 0.15 \\
$\mathrm{CaO}(\%)$ & 4.44 & 1.13 \\
$\mathrm{MgO}(\%)$ & 1.90 & 0.38 \\
$\mathrm{Na}_{2} \mathrm{O}(\%)$ & 1.35 & 0.15 \\
$\mathrm{Fe}(\mathrm{mg} / \mathrm{kg})$ & 1180 & 1210 \\
$\mathrm{Mn}(\mathrm{mg} / \mathrm{kg})$ & 1160 & 28 \\
\hline
\end{tabular}

the adsorbent is closely related to the metal oxides and hydroxides in the adsorbent [18]. Metal oxides such as $\mathrm{K}_{2} \mathrm{O}, \mathrm{CaO}, \mathrm{MgO}$, and $\mathrm{Na}_{2} \mathrm{O}$ in BTP-FA are higher than those in CTP-FA, which explains why BTP-FA exhibits strong alkalinity.

\section{Methods}

\section{Adsorption characteristics}

The phosphate adsorption properties of BTP-FA/CTPFA were investigated by varying different environmental parameters, such as initial phosphate concentration, $\mathrm{pH}$, BTP-FA/CTP-FA dose, and reaction time. The influence of initial phosphate concentration on phosphate adsorption properties of BTP-FA was determined. Multiple solutions with different initial phosphate concentrations were obtained by diluting a phosphate-containing solution stepwise from 10 to $1000 \mathrm{mg} / \mathrm{L}$. The initial $\mathrm{pH}$ of each solution was adjusted to $\mathrm{pH} 6$ using $0.1 \mathrm{M} \mathrm{HCl}$ and $\mathrm{NaOH}$. $25 \mathrm{~mL}$ of each of the phosphate solutions was added into a $50 \mathrm{~mL}$ polyethylene tube containing 0.2 $\mathrm{g}$ of BTP-FA/CTP-FA. All samples were stirred for $24 \mathrm{~h}$ at $175 \mathrm{rpm}$ in a shaker incubator and were then filtered using filter paper (filter paper No. 6, ADVANTEC, Roshi Kaisha, Japan). The concentration of phosphate in the filtrate was determined using a UV-VIS spectrometer (X-ma3000PC, Human Corporation, Korea) according to the molybdenum blue-ascorbic acid method [19]. The amount of phosphate absorbed by the fly ash was calculated using the difference between the initial phosphate concentration and the equilibrium phosphate concentration after adsorption (Eq. 1).

$$
q_{e}=\frac{\left(C_{i}-C_{0}\right) \times V}{W}
$$

where $q_{e}, C_{i}, C_{0}, V$, and $W$ are the amount of phosphate adsorbed in equilibrium $(\mathrm{mg} / \mathrm{g})$, initial phosphate concentration $(\mathrm{mg} / \mathrm{L})$, phosphate concentration in equilibrium $(\mathrm{mg} / \mathrm{L})$, volume of solution $(\mathrm{mL})$, and BTP-FA/ CTP-FA dose (g), respectively. 
Additional adsorption experiments were conducted to study the effect of different experimental parameters: the initial $\mathrm{pH}$ was varied from 2 to 10; the BTP-FA dose was varied from 1.25 to $40 \mathrm{~g} / \mathrm{L}$; and the reaction time was varied from 0.13 to $24 \mathrm{~h}$. Subsequent experiments analyses were performed in the same manner as described above. All experiments in this study were performed with three replications. In addition, to provide clear information on phosphate adsorption by BTP-FA, the results, according to the initial phosphate concentration and reaction time, were fitted to isothermal adsorption models [Freundlich isotherm model (FI-model) and Langmuir isotherm model (LI-model)] and kinetic model [pseudo-first-order model (PF-model), pseudo-second-order model (PSmodel), and intraparticle diffusion model (ID-model)].

\section{Mechanisms}

A sample for evaluating the mechanism of phosphate adsorption by BTP-FA was prepared by stirring a polyethylene tube containing a $500 \mathrm{mg} / \mathrm{L}$ phosphate solution $(25 \mathrm{~mL})$ and $0.2 \mathrm{~g}$ of BTP-FA for $24 \mathrm{~h}$, followed by filtration and drying. In this study, changes in the surface structure, element distribution, and functional groups of BTP-FA were investigated, before and after the adsorption of phosphate, using scanning electron microscopeenergy dispersive X-ray spectrometer (SEM-EDS, Philips XL 30S FEG, Netherlands) and Fourier-transform infrared spectroscopy (FTIR, Spectrum Two, PerkinElmer, USA).

\section{Results and discussion}

\section{Effects of initial phosphate concentration}

The adsorption characteristics of phosphate by BTP-FA and CTP-FA according to the initial phosphate concentration are shown in Fig. 1A. The amount of phosphate adsorbed by CTP-FA started reducing when the initial phosphate concentration was $20 \mathrm{mg} / \mathrm{L}$, which is a low concentration, and the adsorbed amount further reduced as the initial phosphate concentration increased. This indicates that the active sites capable of adsorbing phosphate in CFP-FA were easily saturated by phosphate [20]. Conversely, BTP-FA adsorbed almost all the dissolved phosphate when the initial phosphate concentration ranged from 20 to $200 \mathrm{mg} / \mathrm{L}$; the phosphate adsorption sites in BTP-FA gradually became saturated as the initial phosphate concentration was raised above $500 \mathrm{mg} / \mathrm{L}$.

The adsorption patterns of phosphate by both BTPFA and CTP-FA were relatively suitable for the L-type. This indicates that the adsorption-active sites that existed inside and outside the adsorbent became saturated due to the increased concentration of pollutants, and the amount of pollutants adsorbed by the adsorbent did not increase, but remained constant

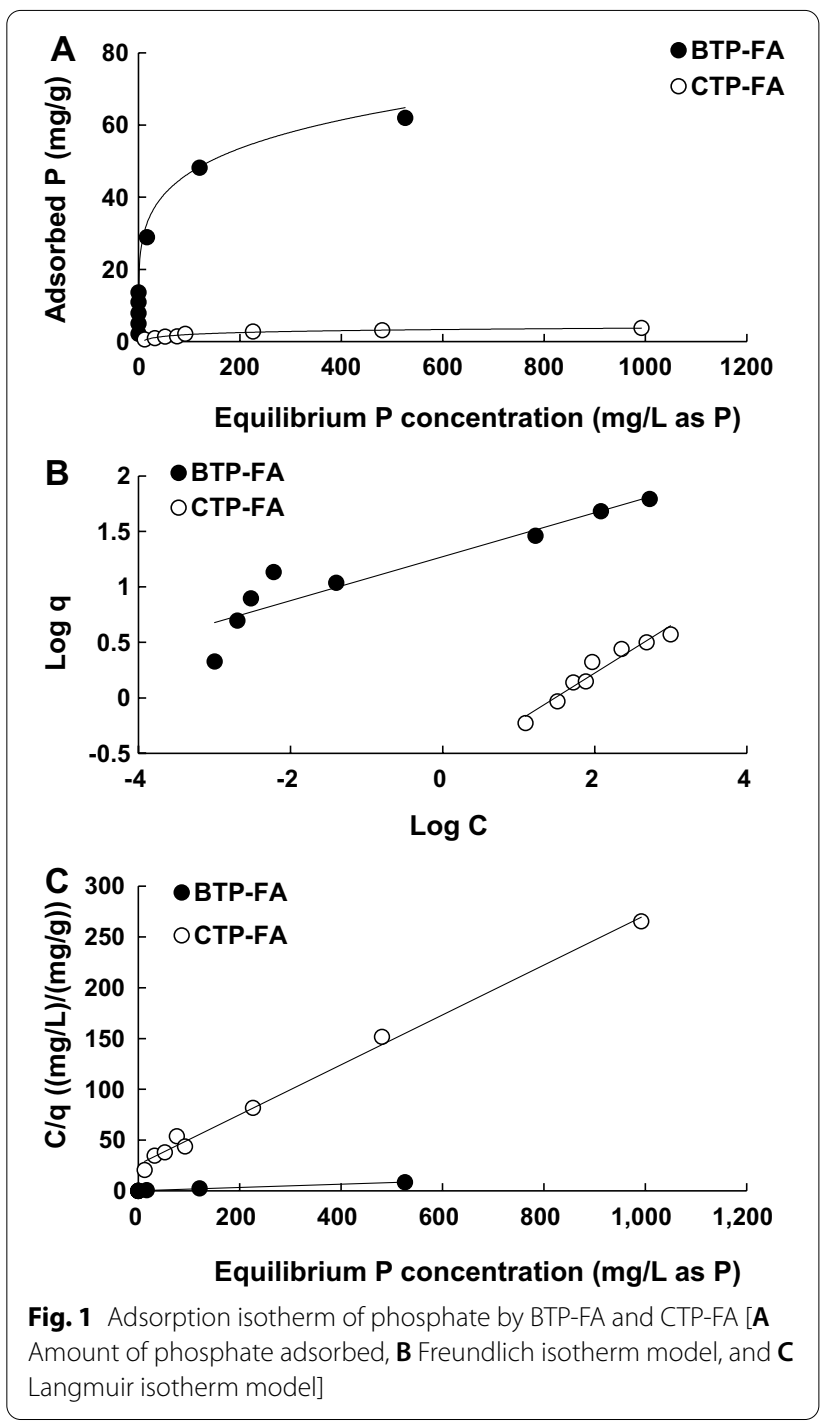

[21]. To present the adsorption characteristics of phosphate by BTP-FA and CTP-FA more clearly, the actual adsorption results were fitted to the FI- and LI-models (Fig. 1B, C), respectively, and the constants and coefficients of determination derived from each model equation are summarized in Table 2. The adsorption results of phosphates by BTP-FA and CTP-FA were better fit to the LI-model $\left(R^{2}=0.9950\right.$ for BTP-FA and 0.9947 for CTP-FA) than the FI-model $\left(R^{2}=0.9162\right.$ for BTPFA and 0.9411 for CTP-FA). The fact that the pollution adsorption results are suitable for the FI-model indicates a typical physical adsorption, where the adsorbed pollutants accumulate on the surface of the adsorbent with heterogeneous active sites [22]. In contrast, the LI-model represents a typical chemical adsorption in which adsorbed contaminants form a single molecule 
Table 2 The parameter estimates and coefficients of determination $\left(R^{2}\right)$ for fit of the isotherm equation to experimental data of phosphate adsorption by BTP-FA and CTP-FA

\begin{tabular}{llll}
\hline Models & Parameters & BTP-FA & CTP-FA \\
\hline Freundlich & $K$ & 18.96 & 0.23 \\
& $1 / n$ & 0.198 & 0.428 \\
Langmuir & $R^{2}$ & 0.916 & 0.9411 \\
& $a(\mathrm{mg} / \mathrm{g})$ & 62.1 & 4.1 \\
& $b(\mathrm{~L} / \mathrm{mg})$ & 0.148 & 0.010 \\
\hline
\end{tabular}

layer on the surface of an adsorbent with homogenous active sites [17]. From these results, it is considered that the adsorption of phosphate by BTP-FA and CTP-FA is controlled by chemisorption. The maximum phosphate adsorption capacity of BTP-FA and CTP-FA derived from the Langmuir isothermal adsorption model were 62.1 and $4.1 \mathrm{mg} / \mathrm{g}$, respectively, and the amount of phosphate adsorbed by BTP-FA was approximately 15 times higher than that by CTP-FA.

The difference in phosphate adsorption capacity between BTP-FA and CTP-FA is considered to be closely related to their properties. $\mathrm{Xu}$ et al. [23] reported that phosphate removal by fly ash was dominantly influenced by surface adsorption/precipitation due to the calcium contained in fly ash. As demonstrated in Table 2, the calcium content of CTP-FA is lower than that of BTP-FA. In addition, it is known that $\mathrm{pH}$ is an important factor that influences the surface adsorption/precipitation of phosphate by calcium, and it is formed by the reaction between calcium dissolved from the adsorbent and phosphate ions above $\mathrm{pH} 8.5$ [24]. After the phosphate adsorption reaction of BTPFA and CTP-FA (initial phosphate concentration: 500 $\mathrm{mg} / \mathrm{L}$ and initial $\mathrm{pH} 7$ ), the final $\mathrm{pH}$ of the solutions was 8.86 and 7.22, respectively. As such, CTP-FA did not cause a sufficient $\mathrm{pH}$ rise for the surface adsorption/ precipitation of phosphate.

The concentration of Ca released from BTP-FA and CTP-FA with or without, phosphate is shown in Fig. 2. The concentration of Ca released from CTP-FA was higher in the solution containing phosphate compared to that in the phosphate-free solution. In contrast, the concentration of calcium released by BTP-FA was lower in the phosphate-containing solution compared to that in the phosphate-free solution. These results indicate that the surface adsorption/precipitation of phosphate in CTP-FA did not occur due to reaction with $\mathrm{Ca}$, and that the removal of phosphate by BTP-FA is dominantly influenced by the surface adsorption/precipitation reaction with $\mathrm{Ca}$.

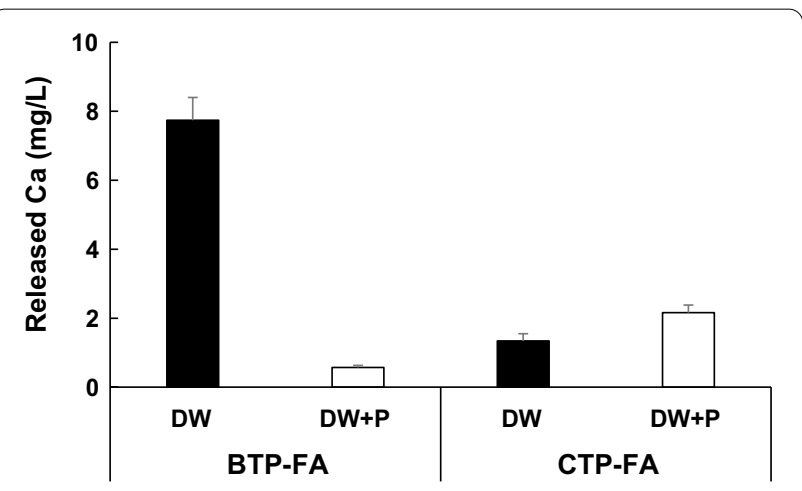

Fig. 2 Concentration of Ca released from BTP-FA and CTP-FA in solution with and without phosphate during adsorption reaction

The affinity of CTP-FA for phosphate is extremely low compared to that of BTP-FA. Accordingly, it is believed that CTP-FA will be limited in its use as an adsorbent for phosphate removal. Owing to its high phosphate adsorption capacity and favorable characteristics, BTP-FA is a promising adsorbent for treating phosphate contamination in various environmental conditions in the future.

\section{Effects of time}

The phosphate adsorption characteristics of BTPFA according to the reaction time were determined at phosphate concentrations of 250,500, and 1000 $\mathrm{mg} / \mathrm{L}$ (Fig. 3). The adsorption of phosphate by BTPFA rapidly increased at the beginning of the reaction, regardless of the initial phosphate concentration and almost reached saturation within $2 \mathrm{~h}$ of the reaction. Although the amount of phosphate adsorbed by BTPFA increased slightly after $2 \mathrm{~h}$, the increase was insignificant. In particular, the adsorption of phosphate by BTP-FA was divided into two stages; fast adsorption in the early stage and slow adsorption in the late stage. The fast adsorption in the early stage occurred because the active sites that could adsorb phosphate in BTP-FA were empty, whereas the slow adsorption in the late stage occurred because the adsorption sites in BTP-FA 

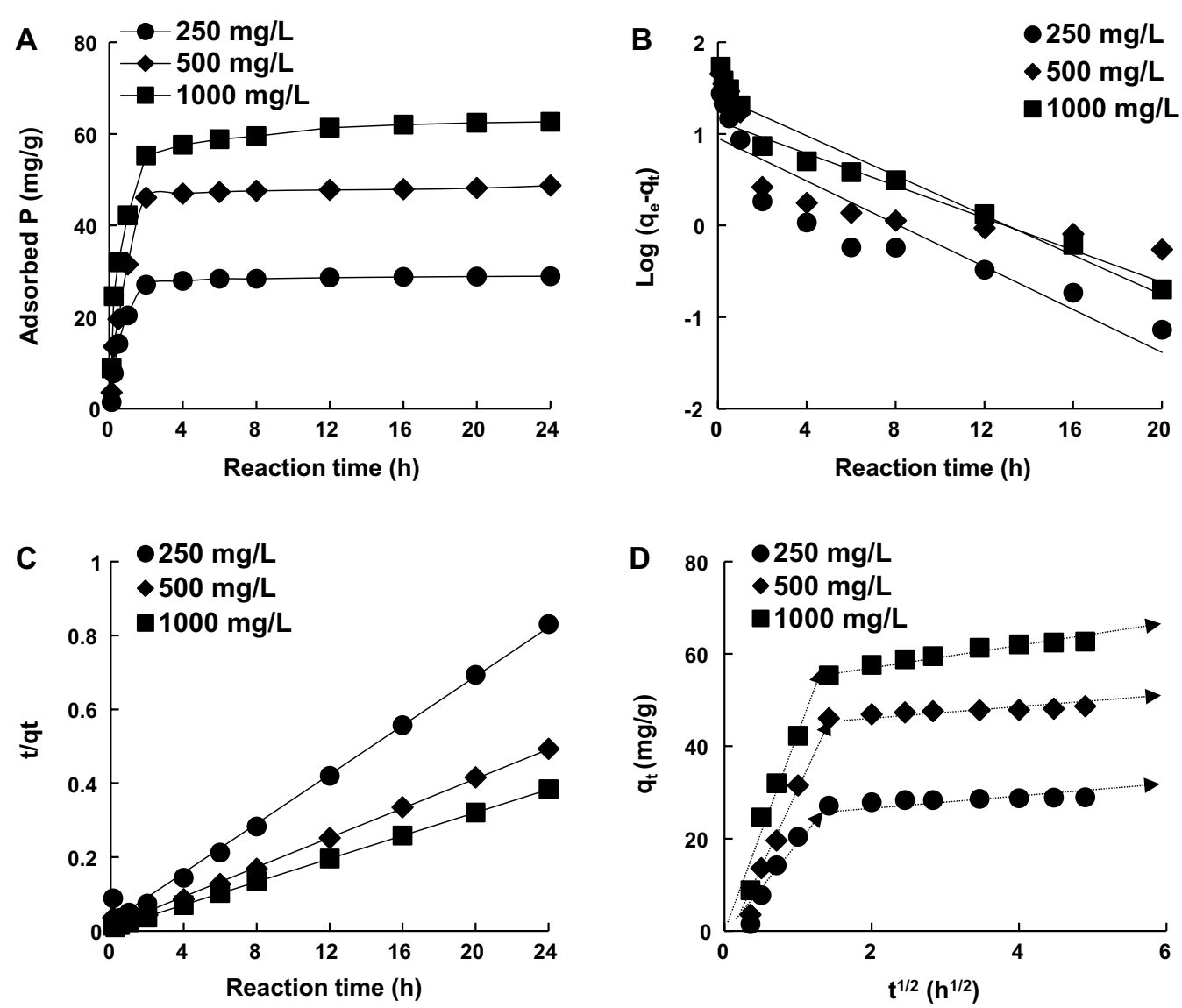

Fig. 3 Effects of contact time on phosphate adsorption by BTP-FA at different initial phosphate concentration [A Adsorbed phosphate, B Pseudo-first-order model, C Pseudo-second-order model, and $\mathbf{D}$ Intraparticle diffusion model]

were saturated [25-27]. In terms of the precipitation reaction, the rapid adsorption that was observed initially indicated a rapid reaction between Ca dissolved from BTP-FA and phosphate ions. Conversely, the slow adsorption at the late stage meant that calcium is no longer dissolved from BTP-FA and the phosphate adsorption reaction had reached equilibrium.

The actual adsorption amount was fitted with the kinetic model of the PF- and PS-models in order to present the behavior of phosphate more clearly by BTP-FA according to the reaction time (Fig. 3). The constants and coefficients of determination derived from the two model equations are summarized in Table 3 . The amount of phosphate adsorbed by BTP-FA was better matched with the PS-model $\left(R^{2}=0.9948\right.$ at $250 \mathrm{mg} / \mathrm{L}, 0.9979$ at 500 $\mathrm{mg} / \mathrm{L}$, and 0.9998 at $1000 \mathrm{mg} / \mathrm{L}$ ) than with the PF-model $\left(R^{2}=0.8321\right.$ at $250 \mathrm{mg} / \mathrm{L}, 0.6763$ at $500 \mathrm{mg} / \mathrm{L}$, and 0.9334 at $1000 \mathrm{mg} / \mathrm{L}$ ), indicating that the adsorption rate of phosphate by BTP-FA was controlled by a chemical reaction $[28,29]$. The effect of the initial phosphate concentration on the temporal pattern of phosphate adsorption
Table 3 The parameter estimates and coefficients of determination $\left(R^{2}\right)$ for fit of the kinetic equation to experimental data of phosphate adsorption by BTP-FA at different initial phosphate concentration

\begin{tabular}{lllcc}
\hline Models & Parameters & $\mathbf{2 5 0} \mathbf{~} \mathbf{g} / \mathbf{L}$ & $\mathbf{5 0 0} \mathbf{~} \mathbf{g} / \mathbf{L}$ & $\mathbf{1 0 0 0} \mathbf{~} \mathbf{g} / \mathbf{L}$ \\
\hline Pseudo-first-order & $q_{e}(\mathbf{m g} / \mathrm{g})$ & 8.97 & 13.70 & 25.9 \\
& $k_{1}(1 / \mathrm{h})$ & 0.269 & 0.202 & 0.250 \\
& $R^{2}$ & 0.832 & 0.676 & 0.933 \\
Pseudo-second- & $q_{e}(\mathrm{mg} / \mathrm{g})$ & 30.12 & 50.25 & 64.10 \\
order & & & & \\
& $k_{2}(\mathrm{~g} / \mathrm{mg} \cdot \mathrm{h})$ & 0.041 & 0.030 & 0.030 \\
& $R^{2}$ & 0.995 & 0.998 & 0.999 \\
Intraparticle diffu- & $k_{i 1}$ & 23.49 & 38.76 & 40.50 \\
sion & $R^{2}$ & 0.964 & 0.990 & 0.947 \\
& $k_{i 2}$ & 0.46 & 0.62 & 2.07 \\
& $R^{2}$ & 0.846 & 0.921 & 0.943 \\
\hline
\end{tabular}

by BTP-FA was negligible, and the amount of phosphate adsorbed increased depending on the initial phosphate 
concentration. This is believed to be due to an increase in the collision frequency as well as the chemical reaction between phosphate and BTP-FA.

In general, the two-stage adsorption reaction of pollutants by the adsorbent is divided into adsorption by the external boundary layer and adsorption by intraparticle diffusion in the pores [30]. To determine their effects, the actual adsorption amount was applied to the ID-model (Fig. 3; Table 3). The adsorption of phosphate by BTPFA was dominantly influenced by the external boundary layer of the adsorbent, and the reaction rate at the external boundary layer $\left(k_{i 1}\right)$ and that of internal diffusion $\left(k_{i 2}\right)$ increased as the initial phosphate concentration increased.

\section{Effects of initial $\mathrm{pH}$}

The effect of the initial $\mathrm{pH}$ on the phosphate adsorption properties of BTP-FA is shown in Fig. 4A. At an initial $\mathrm{pH} 2$, the amount of phosphate adsorbed by BTP-FA was $16.5 \mathrm{mg} / \mathrm{g}$, and as the $\mathrm{pH}$ increased from $\mathrm{pH} 3$ to $\mathrm{pH}$ 5 , the amount of adsorbed phosphate increased to 46.7 $\mathrm{mg} / \mathrm{g}$. In addition, the amount of phosphate adsorbed by BTP-FA did not change significantly when the initial was changed from $\mathrm{pH} 5$ to $\mathrm{pH} 8$, and it remained in the range of $46.7-47.3 \mathrm{mg} / \mathrm{g}$. In contrast, the amount of phosphate adsorbed by BTP-FA tended to decrease gradually as
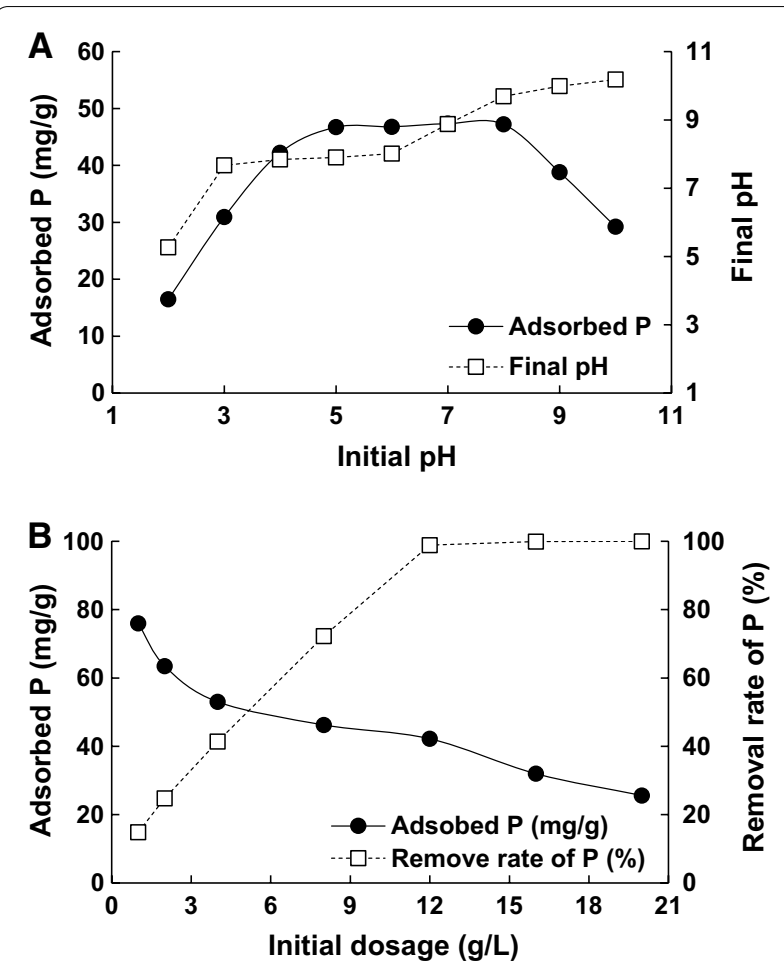

Fig. 4 Effect of initial pH (A) and BTP-FA dosage (B) on phosphate adsorption the initial became $\mathrm{pH} 8$ or higher. In particular, the high adsorption amount of phosphate by BTP-FA when the initial was between $\mathrm{pH} 5$ to $\mathrm{pH} 8$ is due to the effect of the precipitation reaction between phosphate present in the form of $\mathrm{H}_{2} \mathrm{PO}_{4}{ }^{-}$and $\mathrm{HPO}_{4}{ }^{2-}$ and calcium dissolved from BTP-FA [31, 32]. Conversely, the decrease in the amount of phosphate adsorbed at high $\mathrm{pH}$ values is closely related to the surface charge of phosphate and BTP-FA. At high $\mathrm{pH}$, most of the phosphates are negatively charged and the surface of the adsorbent is also negatively charged, so the adsorbed amount is reduced due to electrostatic repulsion between them.

\section{Effects of BTP-FA dose}

The adsorption characteristics of phosphate according to the BTP-FA dosage were investigated by adjusting the dosage of BTP-FA from 1 to $20 \mathrm{~g} / \mathrm{L}$ (Fig. 4B). As the dose of BTP-FA increased, the removal efficiency of phosphate increased, and the removal efficiency of phosphate reached almost $100 \%$ when the dose of BTPFA was $12 \mathrm{~g} / \mathrm{L}$. This is because as the dosage of BTP-FA increases, the number of active sites capable of adsorbing phosphate increases, and the amount of $\mathrm{Ca}$ available to precipitate phosphate increases. However, the amount of phosphate adsorbed per gram of adsorbent decreased as the amount of BTP-FA increased, suggesting that the increased active sites/calcium of BTP-FA were not used only for phosphate adsorption/precipitation. Similar results and theories have been observed in previous studies [33].

\section{Changes of morphology and functional group}

The surface structure and element distribution characteristics of BTP-FA before and after phosphate adsorption, which were observed through SEM-EDS, are shown in Fig. 5. The surface structure of BTP-FA was similar, regardless of phosphate adsorption. The proportion of $\mathrm{K}$ in BTP-FA before phosphate adsorption was as high as $8.67 \%$, but it was mostly lost during the phosphate adsorption process, and only $2.66 \%$ remained in BTP-FA after the adsorption. The proportion of $\mathrm{Na}$ in BTP-FA before and after phosphate adsorption was also similar to that of $\mathrm{K}$. Alkali oxides, such as $\mathrm{K}_{2} \mathrm{O}$ and $\mathrm{Na}_{2} \mathrm{O}$ in fly ash, are easily dissolved and cause an increase in the $\mathrm{pH}$ of the solution during the adsorption reaction [17]. It is considered that the adsorption of phosphate by BTPFA is enhanced due to the increase in $\mathrm{pH}$ that occurs when these oxides dissolve. In particular, there was no phosphorus in BTP-FA before phosphate adsorption, but a peak related to phosphorus in BTP-FA was clearly observed after phosphate adsorption, showing a distribution ratio of $3.7 \%$. In contrast, the distribution ratio of calcium in BTP-FA was $5.7 \%$ before, and $5.9 \%$ after the 

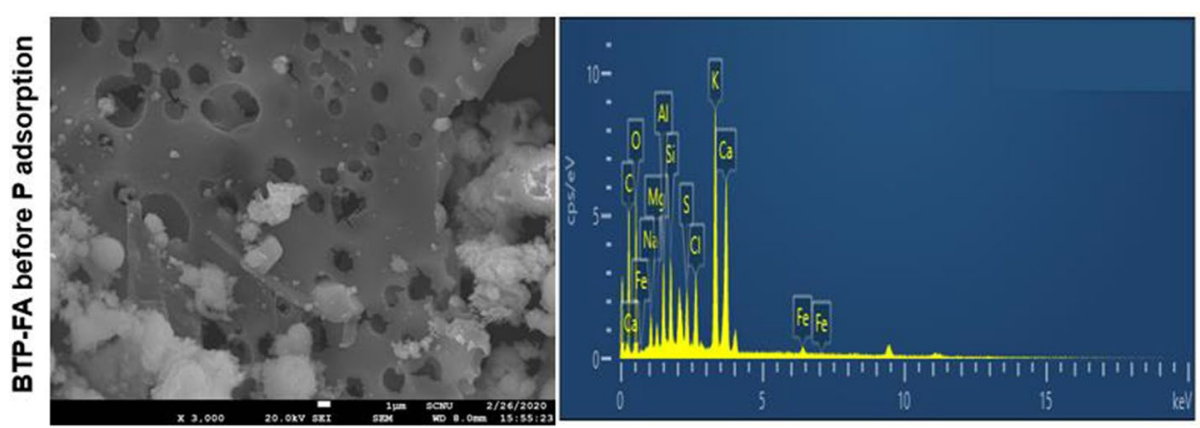

\begin{tabular}{lr}
\hline Element & Atomic \% \\
$\mathrm{C}$ & 32.25 \\
$\mathrm{O}$ & 34.27 \\
$\mathrm{Na}$ & 5.50 \\
$\mathrm{Mg}$ & 2.73 \\
$\mathrm{Al}$ & 3.92 \\
$\mathrm{Si}$ & 3.86 \\
$\mathrm{~S}$ & 1.27 \\
$\mathrm{Cl}$ & 1.47 \\
$\mathrm{~K}$ & 8.67 \\
$\mathrm{Ca}$ & 5.72 \\
$\mathrm{Fe}$ & 0.34 \\
Total: & 100.00 \\
\hline
\end{tabular}
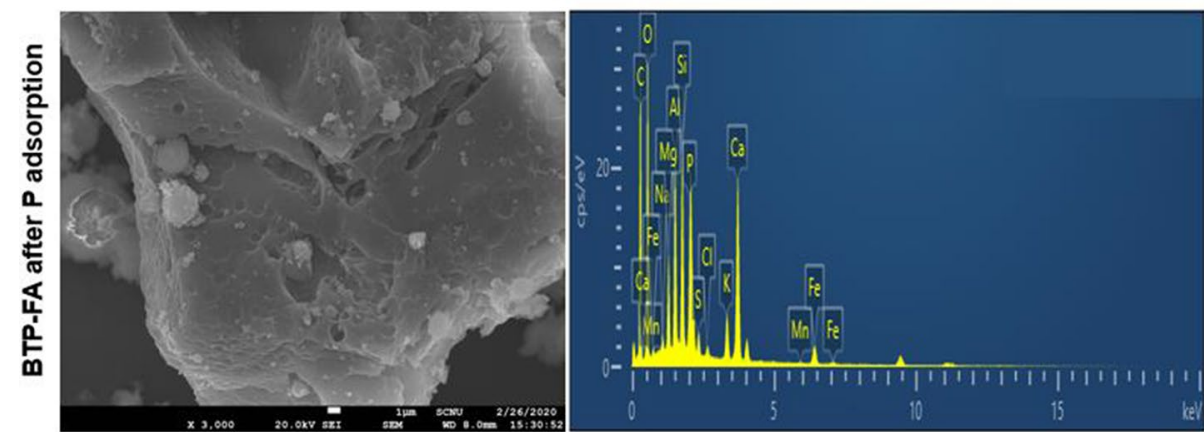

\begin{tabular}{lr}
\hline Element & Atomic \% \\
\hline $\mathrm{C}$ & 20.18 \\
$\mathrm{O}$ & 49.03 \\
$\mathrm{Na}$ & 1.42 \\
$\mathrm{Mg}$ & 4.68 \\
$\mathrm{Al}$ & 5.70 \\
$\mathrm{Si}$ & 5.59 \\
$\mathrm{P}$ & 3.67 \\
$\mathrm{~S}$ & 0.39 \\
$\mathrm{Cl}$ & 0.14 \\
$\mathrm{~K}$ & 2.66 \\
$\mathrm{Ca}$ & 5.88 \\
$\mathrm{Mn}$ & 0.04 \\
$\mathrm{Fe}$ & 0.62 \\
Total: & 100.00 \\
\hline
\end{tabular}

Fig. 5 Morphology and element composition in BTP-FA before and after phosphate adsorption

phosphate adsorption, and they were not very different from each other. According to the method suggested by Miculescu et al. [34], the Ca/P molar ratio in BTP-FA after phosphate adsorption was calculated using the distribution ratios of $\mathrm{Ca}$ and $\mathrm{P}$ derived from the EDS results. The molar ratio of Ca:P in BTP-FA after phosphate adsorption was 1.20 , which was lower than the stoichiometric Ca:P molar ratio in hydroxyapatite (1.67) [35]. This indicates that the phosphate adsorption/precipitation reaction is insufficient to generate perfect hydroxyapatite through the precipitation reaction between calcium dissolved from BTP-FA and phosphate ions.

The changes in the surface functional groups of BTPFA before and after phosphate adsorption, as determined by FTIR, are shown in Fig. 6. The peak generated at a wavelength of $1650 \mathrm{~cm}^{-1}$ in BTP-FA after phosphate adsorption is related to the $-\mathrm{OH}$ vibration band, which is typically attributed to the adsorption of $\mathrm{H}_{2} \mathrm{O}$ [36]. The peak at $618 \mathrm{~cm}^{-1}$ in BTP-FA before phosphate adsorption corresponds to sulfate [37]. However, this peak disappeared as sulfate was dissolved during the phosphate adsorption process. In a previous study, it was reported that peaks assigned at wavelengths of 1052, 984, and 787 $\mathrm{cm}^{-1}$ were related to $\mathrm{H}_{2} \mathrm{PO}_{4}{ }^{-}$and $\mathrm{HPO}_{4}{ }^{2-}$. After phosphate adsorption, these peaks were strongly observed in BTP-FA, indicating that the adsorbed phosphate was partially bound to BTP-FA in the form of $\mathrm{H}_{2} \mathrm{PO}_{4}{ }^{-}$and $\mathrm{HPO}_{4}{ }^{2-}$ [38]. After phosphate adsorption, new peaks

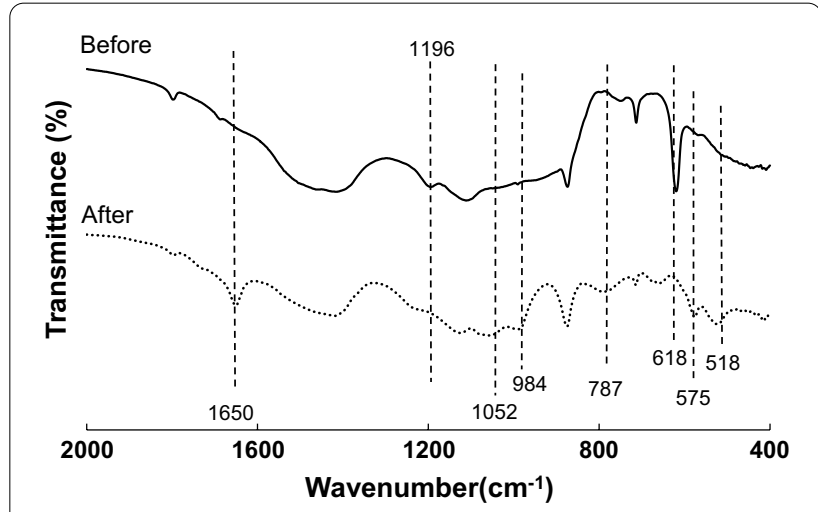

Fig. 6 Changes of functional group in BTP-FA before and after phosphate adsorption

were observed at lower wavelengths of 575 and $518 \mathrm{~cm}^{-1}$ in BTP-FA [39]. In particular, these peaks are known to be closely related to phosphorus in hydroxyapatite. This result suggests that the final product of the phosphate adsorption reaction by BTP-FA was hydroxyapatite. In view of these results, it is concluded that the surface adsorption/precipitation reaction between calcium and phosphate ions, which is supported by the increase in $\mathrm{pH}$ caused by the dissolution of $\mathrm{K}_{2} \mathrm{O}$ and $\mathrm{Na}_{2} \mathrm{O}$, played a decisive role in the removal of phosphate by BTP-FA. 
Recycling fly ash discharged from biomass thermal power plants as phosphate adsorbents is expected to contribute not only to waste reduction, but also to wastewater purification.

\section{Acknowledgements}

This work was supported, in part, by Field Technology Research Project through the Korea South-East Power Co., Ltd. (KOEN), by Korea Institute of Planning and Evaluation for Technology in Food, Agriculture and Forestry (IPET) through Livestock Industrialization Technology Development Program, funded by Ministry of Agriculture, Food and Rural Affairs (MAFRA)(12103403), and a grant from the Ministry of Science and ICT (MSIT) through the National Research Foundation (NRF) of Korea [NRF-2019R1C1C1004572; NRF-2019R1A4A1029125].

\section{Authors' contributions}

J-HP, S-WH and D-CS designed and conducted the experiment as well as wrote the manuscript. S-LL, and J-HL conducted characteristic analysis and interpretation of fly ash used. All authors read and approved the final manuscript.

\section{Funding}

Not applicable.

\section{Availability of data and materials}

All data is available in the main text

\section{Declarations}

\section{Competing interests}

The authors declare that they have no competing interests.

\section{Author details}

${ }^{1}$ Department of Applied Life Chemistry (Institute of Agriculture and Life Science), Gyeongsang National University, Jinju 52828, South Korea. ${ }^{2}$ Division of Applied Life Science (Institute of Agriculture and Life Science), Gyeongsang National University, Jinju 52828, South Korea.

Received: 13 April 2021 Accepted: 12 May 2021

Published online: 20 May 2021

\section{References}

1. Li B, Dong SL, Huang YF, Li P, Yu W, Wang GQ, Young B (2021) Toward a decision support framework for sustainable phosphorus management: a case study of China. J Clean Prod 279:123441

2. Jeong YC, Lee KS (2019) Overexpression, purification, crystallization and preliminary X-ray crystallographic characterization of the receiver domain of the response regulator PhoP from Enterococcus faecalis ATCC 29212. Appl Biol Chem 62:66

3. Wu B, Wan J, Zhang Y, Pan B, Lo IMC (2020) Selective phosphate removal from water and wastewater using sorption: process fundamentals and removal mechanisms. Environ Sci Technol 51:50-66

4. Yang Y, Koh KY, Li R, Zhang H, Yan Y, Chen JP (2020) An innovative lanthanum carbonate grafted microfibrous composite for phosphate adsorption in wastewater. J Hazard Mater 392:121952

5. Awual MR (2019) Efficient phosphate removal from water for controlling eutrophication using novel composite adsorbent. J Clean Prod 228:1311-1319

6. EPA (1987) Phosphorus removal: design manual. Environmental Protection Agency, Washington DC

7. KMOE (2011) Water Quality Standards for Treated Wastewater Based on Its Specific Purpose of Use, Ministry of Environment: Gyeonggi-do, QKorea

8. Yang Q, Wang X, Luo W, Sun J, Xu Q, Chen F, Zhao J, Wang S, Yao F, Wang D, Li X, Zeng G (2018) Effectiveness and mechanisms of phosphate adsorption on iron-modified biochar derived from waste activated sludge. Bioresour Technol 247:537-544
9. Peng H, Guo J (2020) Removal of chromium from wastewater by membrane filtration, chemical precipitation, ion exchange, adsorption electrocoagulation, electrochemical reduction, electrodialysis, electrodeionization, photocatalysis and nanotechnology: a review. Environ Chem Lett 18:2055-2068

10. Arslanoğlu H (2021) Production of low-cost adsorption with small particle size from calcium carbonate rich residue carbonatation cake and their high performance phosphate adsorption applications. J Mater Res Technol 11:428-447

11. Li J, Li B, Huang H, Zhao N, Zhang M, Cao L (2020) Investigation into lanthanum-coated biochar obtained from urban dewatered sewage sludge for enhanced phosphate adsorption. Sci Total Environ 714:136839

12. Wei S, Tan W, Liu F, Zhao W, Weng L (2014) Surface properties and phosphate adsorption of binary systems containing goethite and kaolinite. Geoderma 213:478-484

13. Wang Y, Yu Y, Li H, Shen C (2016) Comparison study of phosphorus adsorption on different waste solid: Fly ash, red mud and ferric-alum water treatment residues. J Environ Sci 50:79-86

14. Li D, Min H, Jiang X, Ran X, Zou L, Fan J (2013) One-pot synthesis of Aluminum-containing ordered mesoporous silica MCM-41 using coal fly ash for phosphate adsorption. J Colloid Interface Sci 404:42-48

15. Li F, Wu W, Li R, Fu X (2016) Adsorption of phosphate by acid-modified fly ash and palygorskite in aqueous solution: experimental and modeling. Appl Clay Sci 132-133:343-352

16. Jambhulkar HP, Shaikh SMS, Kumar MS (2018) Fly ash toxicity, emerging issues and possible implications for its exploitation in agriculture: Indian scenario: a review. Chemosphere 213:333-344

17. Park JH, Eom JH, Lee SL, Hwang SW, Kim SH, Kang SW, Yun JJ, Cho JS, Lee YH, Seo DC (2020) Exploration of potential capacity of fly ash and bottom ash derived from wood pellet-based thermal power plant for heavy metal removal. Sci Total Environ 740:140205

18. Ahmad M, Teel AL, Watts RJ (2010) Persulfate activation by subsurface minerals. J Contam Hydrol 115:34-45

19. APHA-AWWA-WEF (2005) Standard methods for the examination of water and wastewater, 21 st edn. American Public Health Association, Washington, DC

20. Liu J, Zhou Q, Chen J, Zhang L, Chang N (2013) Phosphate adsorption on hydroxyl-iron-lanthanum doped activated carbon fiber. Chem Eng J 215-216:859-867

21. Malana MA, ljaz S, Ashiq MN (2010) Removal of various dyes from aqueous media onto polymeric gels by adsorption process: their kinetics and thermodynamics. Desalination 263:249-257

22. Awe AA, Opeolu BO, Fatoki OS, Ayanda OS, Jackson VA, Snyman R (2020) Preparation and characterization of activated carbon form Vitisvinifera leaf litter and its adsorption performance for aqueous phenanthrene. Appl Biol Chem 63:12

23. Xu K, Deng T, Liu J, Peng W (2010) Study on the phosphate removal from aqueous solution using modified fly ash. Fuel 89:3668-3674

24. Park JH, Wang JJ, Xiao R, Zhou B, Delaune RD, Seo DC (2018) Effect of pyrolysis temperature on phosphate adsorption characteristics and mechanisms of crawfish char. J Colloid Interface Sci 525:143-151

25. Zhang L, Zhang H, Guo W, Tian Y (2014) Removal of malachite green and crystal violet cationic dyes from aqueous solution using activated sintering process red mud. Appl Clay Sci 93-94:85-93

26. Khan TA, Chaudhry SA, Ali I (2015) Equilibrium uptake, isotherm and kinetic studies of $\mathrm{Cd}(\mathrm{II})$ adsorption onto iron oxide activated red mud from aqueous solution. J Mol Liq 202:165-175

27. Lee SL, Park JH, Kim SH, Kang SW, Cho JS, Jeon JR, Lee YB, Seo DC (2019) Sorption behavior of malachite green onto pristine lignin to evaluate the possibility as a dye adsorption by lignin. Appl Biol Chem 62:37

28. Simonin JP (2016) On the comparison of pseudo-first order and pseudosecond order rate laws in the modeling of adsorption kinetics. Chem Eng J 300:254-263

29. Bujdák J (2020) Adsorption kinetics models in clay systems. The critical analysis of pseudo-second order mechanism. Appl Clay Sci 191:105630

30. Arias FEA, Beneduci A, Chidichimo F, Furia E, Straface S (2017) Study of the adsorption of mercury (II) on lignocellulosic materials under static and dynamic conditions. Chemosphere 180:11-23

31. Ruangcharus C, Kim SU, Hong CO (2020) Mechanism of cadmium immobilization in phosphate-amended arable soils. Appl Biol Chem 63:36 
32. Yang S, Zhao Y, Chen R, Feng C, Zhang Z, Lei Z, Yang Y (2013) A novel tablet porous material developed as adsorbent for phosphate removal and recycling. J Colloid Interface Sci 396:197-204

33. Ye J, Cong X, Zhang P, Zeng G, Hoffmann E, Wu Y, Zhang H, Fang W (2016) Operational parameter impact and back propagation artificial neural network modeling for phosphate adsorption onto acid-activated neutralized red mud. J Mol Liq 216:35-41

34. Miculescu F, Luță C, Constantinescu AE, Maidaniuc A, Mocanu AC, Miculescu M, Voicu ŞI, Ciocan LT (2020) Considerations and influencing parameters in EDS microanalysis of biogenic hydroxyapatite. J Funct Biomater 11:82

35. Castro F, Ferreira A, Rocha F, Vicente A, Teixeira JA (2012) Characterization of intermediate stages in the precipitation of hydroxyapatite at $37^{\circ} \mathrm{C}$. Chem Eng Sci 77:150-156

36. Jose A, Nivitha MR, Krishnan JM, Robinson RG (2020) Characterization of cement stabilized pond ash using FTIR spectroscopy. Constr Build Mater 263:120136
37. El-Hamid AMA, Zahran MA, Ahmed YMZ, El-Sheikh SM (2020) Separation of heavy metal ions from petroleum ash liquor using organic resins and FT-IR study of the process. Radiochemistry 62:243-250

38. Elzinga EJ, Sparks DL (2007) Phosphate adsorption onto hematite: an in situ ATR-FTIR investigation of the effects of $\mathrm{pH}$ and loading level on the mode of phosphate surface complexation. J Colloid Interface Sci 308:53-70

39. Chavan PN, Bahir MM, Mene RU, Mahabole MP, Khairnar RS (2010) Study of nanobiomaterial hydroxyapatite in simulated body fluid: formation and growth of apatite. Mate Sci Eng B 168:224-230

\section{Publisher's Note}

Springer Nature remains neutral with regard to jurisdictional claims in published maps and institutional affiliations.

\section{Submit your manuscript to a SpringerOpen ${ }^{\circ}$ journal and benefit from:}

- Convenient online submission

- Rigorous peer review

- Open access: articles freely available online

- High visibility within the field

- Retaining the copyright to your article

Submit your next manuscript at $\boldsymbol{\nabla}$ springeropen.com 